\title{
Lacrimal Gland Lesions Biopsied in a Tertiary Eye Center in Saudi Arabia: A Clinical, Radiological, Surgical, and Histological Review
}

\author{
Walaa Alturkistany ${ }^{1,2}$ \\ Rawan Althaqib' \\ Naif Alsulaiman' \\ Azza Maktabi ${ }^{3}$ \\ Sahar Elkhamary ${ }^{4}$ \\ Hailah Alhussain' \\ 'Oculoplastics Department, King Khalid \\ Eye Hospital, Riyadh, Saudi Arabia; \\ ${ }^{2}$ Ophthalmology Department, King \\ Abdulaziz University Hospital, Jeddah, \\ Saudi Arabia; ${ }^{3}$ Pathology and Laboratory \\ Medicine Department, King Khalid Eye \\ Hospital, Riyadh, Saudi Arabia; \\ ${ }^{4}$ Diagnostic Imaging Department, King \\ Khalid Eye Hospital, Riyadh, Saudi Arabia
}

Correspondence: Walaa Alturkistany

Tel +966504199412

Fax +966II4821908

Email walturkistany@gmail.com
Purpose: To study the demographics and clinical presentation of biopsied lacrimal gland lesions in a tertiary eye center and determine the accuracy of radiological imaging and blood investigations in reaching the diagnosis. We also studied the histopathological outcome of different lacrimal gland biopsy approaches.

Materials and Methods: A retrospective review of patients' charts from 2014 to 2021 who underwent lacrimal gland biopsy. The data collected included demographics, clinical presentations, surgical approaches used, blood workup done, and histopathological and radiological diagnoses. The accuracy of radiological imaging in diagnosing lacrimal gland pathologies was evaluated by comparing radiological interpretation to the final pathological report.

Results: In a total of 48 cases, the most common lacrimal gland lesion was nonspecific inflammation of the lacrimal gland $(34 \%, \mathrm{n}=17)$ followed by lymphoproliferative lesions $(25 \%, n=12)$. Females $(62.5 \%, n=30)$ were more affected than males $(37.5 \%, n=18)$. Other lesions included pleomorphic adenoma, angiolymphoid hyperplasia with eosinophilia, and IgG4 disease. Complete blood investigations were performed in $45.8 \%$ of patients and a systemic disease was found in only $18.2 \%$. The initial assumptive diagnosis based on MRI and CT scan images was congruous with the histopathological diagnosis in $42 \%$ and $12 \%$, respectively. Three surgical approaches were used for incisional biopsy in this study, including sub-periosteal, trans-septal, and palpebral lobe biopsy. Lateral orbitotomy was done in all excisional biopsy cases. We found no statistical difference in the histopathological outcome between the different surgical approaches used.

Conclusion: Nonspecific inflammation and lymphoproliferative disorders are the most common causes of lacrimal gland lesions. Blood work-up should not be used to waive off the need for lacrimal gland biopsy, and the diagnosis should preferably be based on histopathology results. The MRI is a useful tool to diagnose lacrimal gland lesions; however, histopathology remains the gold standard method.

Keywords: lacrimal gland, histopathology, dacryoadenitis, lymphoproliferative, nonspecific inflammation, biopsy

\section{Introduction}

Lacrimal gland lesions are relatively rare, with an estimated incidence of $1.3 / 1,000,000$ / year. ${ }^{1}$ The spectrum of lacrimal gland enlargement pathologies can range from benign self-limiting to systemic life-threatening conditions. ${ }^{2}$ The clinical picture varies, ranging from painless incidental finding to painful swelling with proptosis and globe dystopia. ${ }^{3}$ Lacrimal gland swelling is a nonspecific sign that can be a part of the atypical presentation of serious conditions, such as autoimmune disorders and systemic malignancies. 
Therefore, a lacrimal gland biopsy can be of great value in early detection and management of such conditions. ${ }^{4,5}$ Imaging can play a vital role in diagnosing lacrimal gland pathologies. Certain radiological features, such as the size and consistency of the lacrimal gland and the nature of the surrounding orbital tissues as the orbital bones, globe, and extraocular muscles, may be useful in reaching a diagnosis. ${ }^{6,7}$ Lacrimal gland molding around the orbital structures without causing indentation is a feature seen in lymphoproliferative disorders of the lacrimal gland. With lacrimal gland epithelial tumors, bone remodeling may be seen as pleomorphic adenoma. On the contrary, orbital bony destruction mostly suggests malignant lesions of the lacrimal gland as adenoid cystic carcinoma. All of these unique radiological features are very helpful and reflect the importance of radiology as an essential investigative tool. However, due to overlapping clinical and radiological characteristics between some lacrimal gland disorders, surgical biopsy may be essential to confirm the final diagnosis. ${ }^{6-8}$ Several studies described the histopathological distribution of lacrimal gland lesions worldwide. ${ }^{1-5,9-11}$ This is the first study in the Saudi population that reviewed the clinical, demographics, radiological, histopathological, and surgical approaches in patients with biopsied lacrimal gland lesions.

To the best of our knowledge, there is no previous study examining the histopathological outcome of different surgical approaches in lacrimal gland biopsies.

\section{Materials and Methods}

This was a retrospective study. We reviewed charts of patients who underwent lacrimal gland biopsy from 2014 to May 2021 in King Khaled Eye Specialist Hospital (KKESH) in Riyadh, Saudi Arabia. We included both incisional and excisional biopsies of the lacrimal gland. Normal lacrimal gland histopathology, extrinsic lesions, or secondary invading tumors were excluded.

The King Khaled Eye Specialist Hospital Institutional Review Board approved the study and its protocol adhered to the Declaration of Helsinki's ethical principles.

Information retrieved for each patient included age, gender, laterality, symptoms, duration of symptoms before ophthalmological consultation, histopathological report, imaging performed, and blood work. Lab work was reviewed for all patients labeled on the histopathological report as having non-specific inflammation in order to check for other systemic etiologies. The IgG4-related dacryoadenitis was diagnosed when the comprehensive diagnostic criteria for "definite" or "probable" IgG4related disease were satisfied. Other conditions, such as lymphoproliferative disorders, were diagnosed based on the histopathological results.

The accuracy of radiological imaging in diagnosing lacrimal gland pathologies was evaluated by comparing the radiological interpretation to the final pathological report. We also studied the histopathological outcome of different lacrimal gland incisional biopsy techniques, namely transeptal, subperiosteal, and palpebral lobe approaches.

\section{Transeptal Approach}

The eyelid crease on the affected side was marked and injected with a local anesthetic. The skin and orbicularis fibers were incised. Blunt dissection was carried out until we reached the septum. The septum was opened and the underlying preaponeurotic fat identified. The lacrimal gland was then identified lateral to the preaponeurotic fat. The gland was mobilized and Westcott scissors were used to take a biopsy. Complete hemostasis was achieved prior to skin closure.

\section{Anterolateral Orbitotomy (Sub-Periosteal) Approach}

The eyelid crease on the affected side was marked and injected with a local anesthetic. The skin and orbicularis fibers were incised. Blunt dissection occurred in the suborbicularis pre-septal plane until reaching the superior lateral orbital rim. The periosteum was then incised $2 \mathrm{~mm}$ superior to the superior lateral orbital rim. The periosteum was further cleaned using a combination of cottonoid sponges and freer elevator. Holding the lip of the periosteal incision edge, the freer periosteal elevator is used to dissect into the orbit superolaterally. The periorbital was incised to expose the lacrimal gland, then the biopsy was obtained with either a No. 15 blade or blunt-tipped Westcott scissors.

\section{Palpebral Lobe Biopsy}

A local anesthetic was injected, and the upper lid was retracted with a Desmarres retractor to expose the superolateral fornix. Fluorescein-assisted direct assessment of tears from ductular openings of the palpebral lobe was done intraoperatively to preserve them. Then, a small wedge-like biopsy was excised from the palpebral lobe of the lacrimal gland using Westcott scissors.

The primary objective was to report the demographics and histopathological distribution of common lacrimal 
gland lesions in the Saudi population. The secondary objectives were accuracy of radiological interpretation and blood investigations of lacrimal gland lesions when compared to histopathology. The tertiary objective was to look at the histopathological outcome of different surgical approaches performed in our center.

\section{Data Analysis}

All data were tabulated in Microsoft Excel 2010 spreadsheet (Microsoft Corporation, Redmond, Washington) and analyzed using STATA software version 16.0 (Stata Corp LLC, College Station, TX, USA). Categorical data were described as frequencies and percentages and compared using the Chisquared or Fisher's exact tests, as appropriate. To summarize the continuous variables, mean and standard deviation or median and interquartile range (IQR) were used; Student's $t$-test was used to compare means.

\section{Results}

\section{Demographics}

Forty-eight patients were included in the study analysis, with a mean age of 33 years (range: 9-65 years). In our study, females $(\mathrm{n}=30,62.5 \%)$ were more affected than males $(n=18,37.5 \%)$. The most common pathology in females was non-specific inflammation of the lacrimal gland $(\mathrm{n}=13,76 \%)$, followed by lymphoproliferative lesions $(\mathrm{n}=7,8 \%)$; contrarily, in males, the most common pathology was lymphoproliferative lesions $(\mathrm{n}=5,42 \%)$, followed by non-specific inflammation $(n=4,24 \%)$.

\section{Clinical Presentation}

The mean duration of complaint before ophthalmological consultation was $5 \pm 8$ months, and the median delay between presentation and lacrimal gland biopsy was 15 days (IQR: 63 days). The most common presenting symptom was eyelid swelling $(n=46,96 \%)$, and unilateral lacrimal gland swelling was more $(n=36,75 \%)$ than bilateral $(n=12,25 \%)$. The right side $(\mathrm{n}=25,52 \%)$ was more affected than the left. Other signs and symptoms included periocular pain $(\mathrm{n}=19,40 \%)$, eyelid erythema $(\mathrm{n}=20,4419 \%)$, proptosis $(\mathrm{n}=15,31 \%)$, dystopia $(n=10,21 \%)$, optic disc edema( $(n=2,4 \%)$, palpable lymph nodes in $(n=3,6 \%)$, and enlarged parotid gland $(n=1,2 \%)$. The most common presenting signs are summarized in Table 1.

Overall, the incidence of bilateral disease was the highest in lymphoproliferative lesions $(\mathrm{n}=4,33 \%)$, followed by sarcoidosis $(\mathrm{n}=3,25 \%), \operatorname{IgG} 4(\mathrm{n}=3,25 \%)$, and nonspecific inflammation $(\mathrm{n}=2,17 \%)$.

\section{Histopathological Distribution}

The histopathological distribution pattern of different lesions is shown in (Table 2). The most common pathology found in our population was non-specific inflammation $(\mathrm{n}=17,35 \%)$, followed by lymphoproliferative lesions $(\mathrm{n}=12,25 \%)$. Among lymphoproliferative lesions in the lacrimal gland, reactive and atypical lymphoid hyperplasia were the most frequent.

Regarding malignant lymphoproliferative lesions, B-cell lymphoma was the most frequent lymphoid malignancy of the lacrimal gland, accounting for $50 \%$ of all lacrimal gland lymphomas.

In the specific inflammation group, IgG4 was the most common pathology. Other causes included sarcoidosis. Angiolymphoid Hyperplasia with Eosinophilia (ALHE), Eosinophilic granulomatosis with polyangiitis (EGPA, formerly Churg-Strauss Syndrome) (Figure 1) and Thyroid related orbitopathy,

We also compared the clinical characteristics of the non-specific inflammation and lymphoproliferative lesion groups. Most cases in these groups were unilateral $(n=21$, 78\%); however, lymphoproliferative lesions had a significantly higher bilateral presentation as compared to non-specific inflammation ( $\mathrm{n}=4$ vs $2 ; 67 \%$ and $33 \%$, respectively) $(\mathrm{p}=0.1)$. The mean age in the non-specific inflammation group was $25.8 \pm 13.5$ years $(95 \%$ confidence intervals (CI): 18.5-33), while it was $40 \pm 12.4$ years $(95 \%$ CI: $31.6-48.4)$ for the lymphoproliferative group ( $t$-test, $\mathrm{p}=0.01$; chi-square test, $\mathrm{p}=0.5$ ). The mean duration of complaint in the lymphoproliferative lesions group was $4 \pm 7$ months versus $7 \pm 12$ months for the non-specific inflammation group $(\mathrm{p}=0.5)$.

Overall, there was no significant difference between the two groups regarding the duration of complaint, gender, and presenting signs, including lid swelling, eyelid erythema, proptosis, pain, tenderness, diplopia, limited ocular motility, and decreased visual acuity ( $p>0.05$ for each comparison). The only marginally statistically significant sign was palpable lymph nodes, which were only present in the lymphoproliferative group $(p=0.07)$.

\section{Correlation of Systemic Work Up, Imaging, and Histopathological Results}

A full blood work-up, including complete blood count and inflammatory and infectious panels, was done in 22/48 cases $(45.8 \%)$, of which the tests were able to diagnose a systemic disease in only $18.2 \%$ of the cases $(p=0.02)$. 
Table I Common Clinical Presentation of Lacrimal Gland Lesions

\begin{tabular}{|c|c|c|c|c|c|c|c|}
\hline Diagnosis & $\begin{array}{l}\text { Gender } \\
M^{\mathrm{a}} / \mathrm{F}^{\mathrm{b}} \\
N=18 / 30\end{array}$ & $\begin{array}{l}\text { Laterality } \\
\text { Bi/Unilateral } \\
\mathrm{N}=12 / 26\end{array}$ & $\begin{array}{l}\text { Decreased } \\
\text { VA }^{c} \\
N=12\end{array}$ & $\begin{array}{l}\text { Lid Swelling } \\
N=46\end{array}$ & $\begin{array}{l}\text { Proptosis } \\
\mathrm{N}=15\end{array}$ & $\begin{array}{l}\text { Erythema } \\
\mathrm{N}=\mathbf{2 0}\end{array}$ & $\begin{array}{l}\text { Pain } \\
N=19\end{array}$ \\
\hline \multicolumn{8}{|l|}{ Epithelial Lesions } \\
\hline \multicolumn{8}{|l|}{ Benign } \\
\hline -Dacryops & $\mathrm{I}(5.5 \%) / 0$ & $0 / 1(3 \%)$ & $\mathrm{I}(8 \%)$ & $\mathrm{I}(2 \%)$ & $\mathrm{I}(6.7 \%)$ & $\mathrm{I}(5 \%)$ & $\mathrm{I}(5 \%)$ \\
\hline$-\mathrm{PA}^{\mathrm{d}}$ & $2(11 \%) / 1(3 \%)$ & $0 / 3(8 \%)$ & $\mathrm{I}(8 \%)$ & $2(4 \%)$ & $3(20 \%)$ & & \\
\hline \multicolumn{8}{|l|}{ Malignant } \\
\hline$-\mathrm{ACC}^{\mathrm{e}}$ & $\mathrm{I}(5.5 \%) / 0$ & $0 / 1(3 \%)$ & $\mathrm{I}(8 \%)$ & $\mathrm{I}(2 \%)$ & $\mathrm{I}(6.7 \%)$ & $\mathrm{I}(5 \%)$ & $\mathrm{I}(5 \%)$ \\
\hline$-S_{C C}^{f}$ & $\mathrm{I}(5.5 \%) / 0$ & $0 / 1(3 \%)$ & $\mathrm{I}(8 \%)$ & $\mathrm{I}(2 \%)$ & $\mathrm{I}(6.7 \%)$ & & $\mathrm{I}(5 \%)$ \\
\hline \multicolumn{8}{|l|}{ Non-epithelial Lesions } \\
\hline - Non-specific inflammation & $5(28 \%) / 12(40 \%)$ & $2(17 \%) / 15(42 \%)$ & $4(33 \%)$ & $17(37 \%)$ & $2(13 \%)$ & $10(50 \%)$ & $10(52 \%)$ \\
\hline \multicolumn{8}{|l|}{-Specific inflammation } \\
\hline $\operatorname{lgG} 4-R^{g}$ & $2(11 \%) / 3(10 \%)$ & $3(25 \%) / 2(6 \%)$ & $\mathrm{I}(8 \%)$ & $5(11 \%)$ & $2(13 \%)$ & $3(15 \%)$ & $\mathrm{I}(5 \%)$ \\
\hline Sarcoidosis & $0 / 3(10 \%)$ & $3(25 \%) / 0$ & & $3(6.5 \%)$ & & & \\
\hline Sjogren Syndrome & $\mathrm{I}(5.5 \%) / 0$ & $0 / 1(3 \%)$ & & $\mathrm{I}(2 \%)$ & & $\mathrm{I}(5 \%)$ & $\mathrm{I}(5 \%)$ \\
\hline Churg-Strauss Syndrome & $0 / 1(3 \%)$ & $0 / I(3 \%)$ & & $\mathrm{I}(2 \%)$ & & & \\
\hline $\mathrm{ALHE}^{\mathrm{h}}$ & $0 / 2(7 \%)$ & $0 / 1(3 \%)$ & & $2(4 \%)$ & & $\mathrm{I}(5 \%)$ & $\mathrm{I}(5 \%)$ \\
\hline TED $^{i}$ & $0 / 1(3 \%)$ & $0 / 2(6 \%)$ & & $\mathrm{I}(2 \%)$ & $\mathrm{I}(6.7 \%)$ & & \\
\hline \multicolumn{8}{|l|}{-Lymphoproliferative Lesions } \\
\hline $\mathrm{RLH}^{\mathrm{i}}$ & $\mathrm{I}(5.5 \%) / 3(10 \%)$ & $0 / 4(11 \%)$ & $\mathrm{I}(8 \%)$ & $4(9 \%)$ & $2(13 \%)$ & & \\
\hline $\mathrm{ALH}^{\mathrm{k}}$ & $\mathrm{I}(5.5 \%) / 3(10 \%)$ & $3(25 \%) / I(3 \%)$ & $\mathrm{I}(8 \%)$ & $4(9 \%)$ & $2(13 \%)$ & $2(10 \%)$ & $2(10.5 \%)$ \\
\hline$E M Z L^{\prime}$ & $\mathrm{I}(5.5 \%) / 0$ & $\mathrm{I}(8 \%) / 0$ & & & & & \\
\hline B cell lymphoma & $2(11 \%) / 0$ & $0 / 2(6 \%)$ & $\mathrm{I}(8 \%)$ & $2(4 \%)$ & & $\mathrm{I}(5 \%)$ & $\mathrm{I}(5 \%)$ \\
\hline T cell lymphoma & $0 / I(3 \%)$ & $0 / I(3 \%)$ & & $\mathrm{I}(2 \%)$ & & & \\
\hline
\end{tabular}

Notes: ${ }^{\mathrm{a}}$ Male, ${ }^{\mathrm{b}} \mathrm{Female},{ }^{\mathrm{C}} \mathrm{Visual}$ acuity, ${ }^{\mathrm{d} P l e o m o r p h i c ~ a d e n o m a, ~}{ }^{\mathrm{e}}$ Adenoid cystic carcinoma, ${ }^{\mathrm{f}}$ Squamous cell carcinoma, ${ }^{\mathrm{g}} \mathrm{gG}$ G4- related disease, ${ }^{\mathrm{h}}$ Angiolympoid hyperplasia with

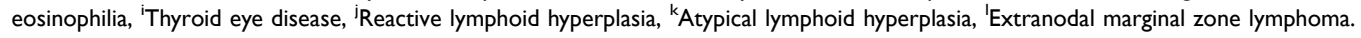

The concordance rates of MRI and CT with histopathology were $42 \%$ and $12 \%(\mathrm{p}=0.2$ and 0.6 , respectively). The radiologist was most correct with diagnosing a pleomorphic adenoma $100 \%(3 / 3)$, followed by nonspecific inflammation $(8 / 15,53 \%)$, and lymphoproliferative lesions $(5 / 12,42 \%)$. (Figure 2) showing pleomorphic adenoma of the lacrimal gland on MRI.

\section{Correlation with Different Surgical Techniques}

In $85 \%$ of the cases $(41 / 48)$, histopathology led to the final diagnosis $(\mathrm{p}=0.3)$. The anterolateral orbitotomy (sub- periosteal) approach was the most frequently performed technique at our center, followed by the transeptal approach. There were no statistically significant differences between the different surgical approaches regarding histopathological outcomes. The transeptal approach was performed in 18/48 cases and the final diagnosis was reached in 15 cases $(83 \%)$, the subperiosteal approach was performed in 22 patients, leading to the final diagnosis in 18 cases (82\%), the palpebral lobe biopsy was done in 5 patients and all reached the final diagnosis, and the lateral orbitotomy for excisional biopsy was performed in 3 cases and all reached the diagnosis $(\mathrm{p}=0.9)$. 
Table 2 Histopathological Distribution of Lacrimal Gland Lesions

\begin{tabular}{|c|c|c|}
\hline Diagnosis & Frequency & Percent \\
\hline \multicolumn{3}{|l|}{ Epithelial Lesions } \\
\hline \multicolumn{3}{|l|}{ Benign } \\
\hline -Dacryops & I & $2 \%$ \\
\hline$-\mathrm{PA}^{\mathrm{a}}$ & 3 & $6 \%$ \\
\hline \multicolumn{3}{|l|}{ Malignant } \\
\hline$-A C C^{b}$ & I & $2 \%$ \\
\hline$-\mathrm{SCC}^{\mathrm{c}}$ & I & $2 \%$ \\
\hline \multicolumn{3}{|l|}{ Non-epithelial Lesions } \\
\hline \multicolumn{3}{|l|}{ Inflammation } \\
\hline -Dacryoadenitis (nonspecific & 17 & $35 \%$ \\
\hline \multicolumn{3}{|l|}{ inflammation) } \\
\hline$-\lg G 4-R D^{d}$ & 4 & $10.5 \%$ \\
\hline -Sarcoidosis & 3 & $6 \%$ \\
\hline$-\mathrm{ALHE}^{\mathrm{e}}$ & 2 & $4 \%$ \\
\hline -Sjogren Syndrome & I & $2 \%$ \\
\hline -Churg-Strauss Syndrome & 1 & $2 \%$ \\
\hline- TED $^{f}$ & I & $2 \%$ \\
\hline \multicolumn{3}{|l|}{ Lymphoproliferative } \\
\hline$-\mathrm{RLH}^{\mathrm{g}}$ & 4 & $8 \%$ \\
\hline$-\mathrm{ALH}^{\mathrm{h}}$ & 4 & $8 \%$ \\
\hline$-E M Z L^{i}$ & I & $2 \%$ \\
\hline -B-cell lymhoma & 2 & $4 \%$ \\
\hline -T-cell lymphoma & I & $2 \%$ \\
\hline
\end{tabular}

Notes: apleomorphic adenoma, ${ }^{b}$ Adenoid cystic carcinoma, 'Squamous cell carcinoma, ${ }^{\text {IgG4 } 4 \text { related disease, }}{ }^{\mathrm{e}}$ Angiolymphoid hyperplasia with eosinophilia, ${ }^{\mathrm{f}}$ Thyroid eye disease, ${ }^{g}$ Reactive lymphoid hyperplasia. hAtypical lymphoid hyperplasia, 'Extranodal marginal zone lymphoma.

The mean number of specimens sent for histopathology for each patient was $2 \pm 1$ pieces, with the number of specimens ranging from 1 to 4 . In 22 patients, only one specimen was obtained, of which the final diagnosis was reached in 21 patients (95\%). 2 specimens were obtained in 11 cases, out of which the sample's histopathological identification matched the final diagnosis in 8 patients (73\%). In the other 10 cases, 3 specimens were obtained for each patient, and 7 specimens were appropriately indicative of the final diagnosis $(70 \%)$. In the remaining 5 cases, 4 specimens were obtained for each patient, and all cases reached the final diagnosis $(100 \%)(p=0.1)$. Multiple specimens were obtained from different sites. The smallest specimen obtained measured $3 \times 2 \mathrm{~mm}$, and the largest one measured $15 \times 10 \mathrm{~mm}$.

\section{An Unusual Case}

A 74-year-old female patient without any previous known medical illness presented to the Emergency Department with a 9-month history of lid swelling and proptosis. Her MRI of the brain and orbit showed right lacrimal gland enlargement with subtle enlargement in the right medial rectus muscle (Figure 3), and the histopathology study demonstrated lymphocytic infiltration in favor of chronic dacryoadenitis (Figure 4). Complete blood work was done that was within normal limits, except for the thyroid function test (TFT), which was in favor of hyperthyroidism. She was diagnosed with lacrimal gland enlargement secondary to thyroid-related orbitopathy (TRO).

\section{Discussion}

The results of our study are comparable to the existing literature regarding the incidence and etiology of lacrimal gland lesions. We found that $61 \%$ of all lacrimal gland biopsies performed show inflammation of the lacrimal

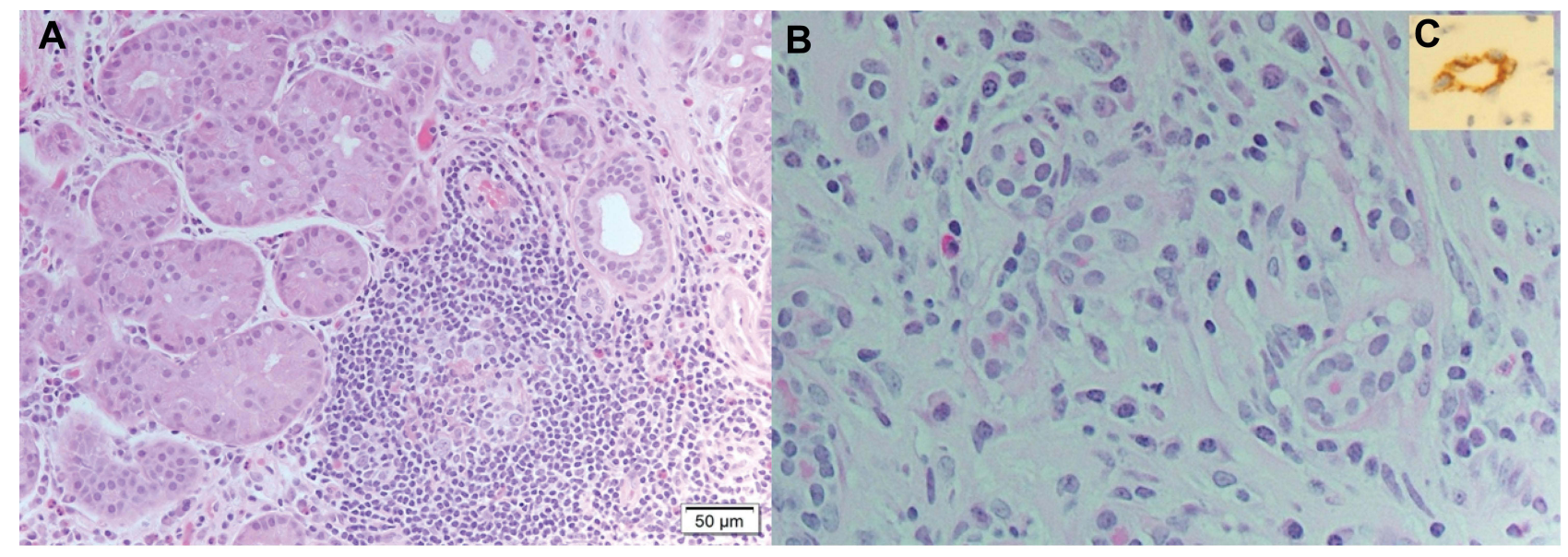

Figure I (A) Histopathology of Lacrimal Gland showing perivascular granulomatous inflammation with eosinophilic infiltration in Eosinophilic granulomatosis with polyangiitis (Haematoxylin-Eosin stain (H\&E), magnification X 200) (B) Angiolymphoid Hyperplasia with Eosinophilia showing endothelial proliferation with scattered eosinophils H\&E, magnification X 200 (C) Cluster of Differentiation. CD34 stain showing endothelial proliferation with plumped endothelial cells of the same patient. 


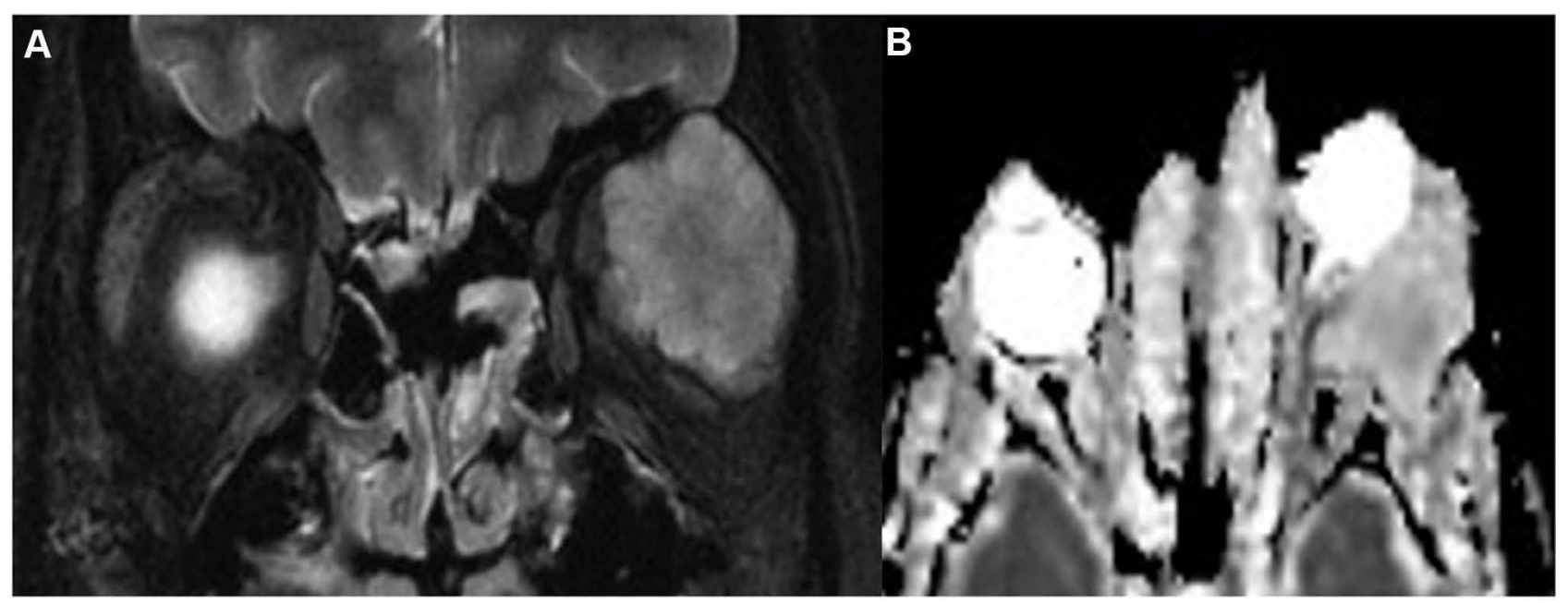

Figure 2 Pleomorphic Adenoma of The Lacrimal Gland; (A) Coronal fat saturated T2-WI and Apparent Diffusion Weight (ADC) image with lobulated outline, (B) Nonrestricted pattern on Diffusion Weight Image (DWI).

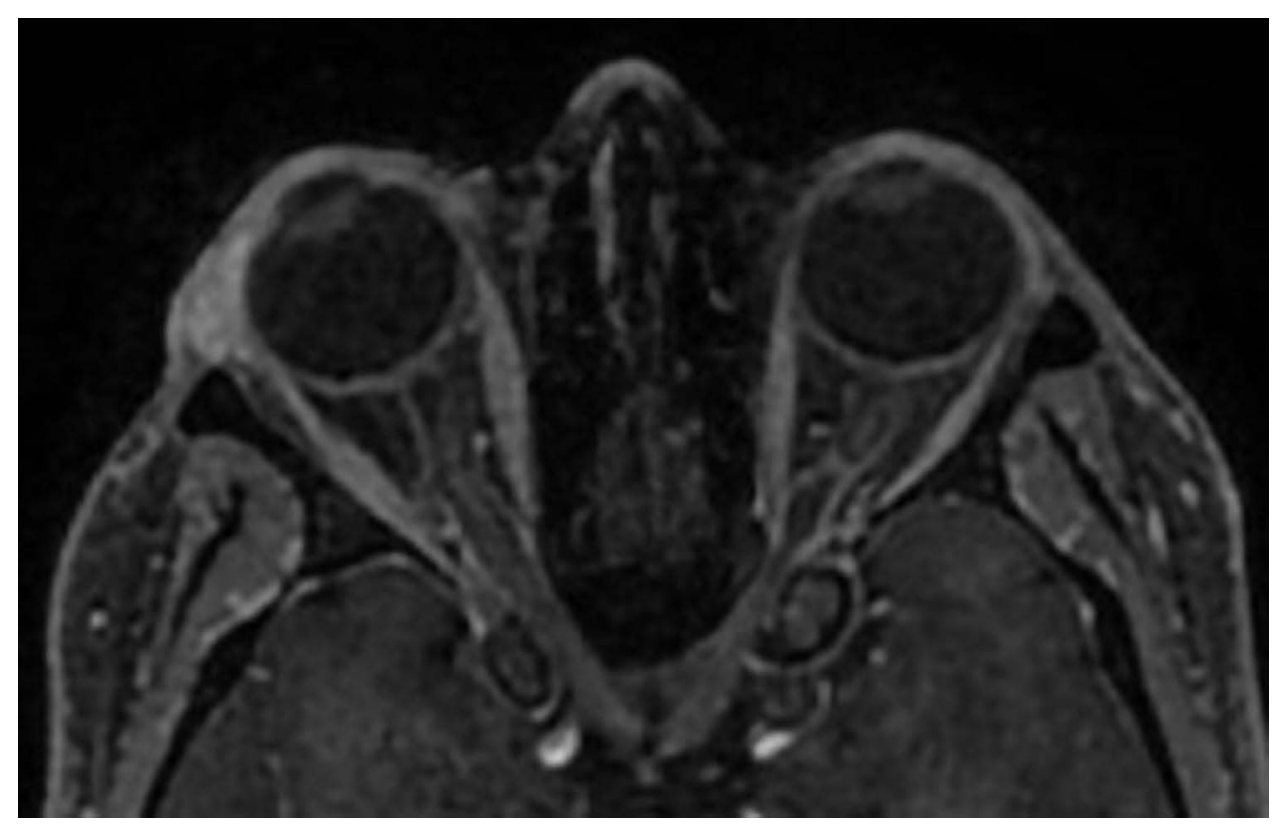

Figure 3 Right lacrimal gland enlargement with subtle enlargement of the right medial rectus muscle sparing the tendinous insertion in Thyroid Related Orbitopathy (TRO).

gland; other studies have also reported similar numbers $63 \%,{ }^{2} 62.5 \%,{ }^{10}$ and $50 \%{ }^{11}$ Further, a systemic association was found in $12 \%$ of our cases, the most common specific etiology being IgG4 disease, like the Korean and Australian studies. ${ }^{9,11}$

We also found that lymphoproliferative lesions were the second most common (24\%) lacrimal gland pathology. ${ }^{2,11}$ Although, reactive lymphoid hyperplasia is considered an inflammation in our center, we classified it as a lymphoproliferative lesion to maintain consistency with other reviews. ${ }^{2,4}$ The most common lymphoma of the lacrimal gland was B-cell (50\%), which is in contrast with Andrew et al, who reported extra-nodal marginal zone lymphoma, EMZL, $(52.8 \%)$ to be the most common lymphoma, followed by follicular variety $(26.4 \%) .{ }^{11}$

The mean age for the non-specific inflammation group was 25.8 years compared to 40 years in the lymphoproliferative group. Our findings concur with previous reviews that lymphoid tumors generally occur in older patients. ${ }^{2}$ Contrarily, the incidence of bilateral disease in patients with lymphoproliferative diseases $(67.0 \%)$ was higher than that in the non-specific inflammation group (33.0\%), 


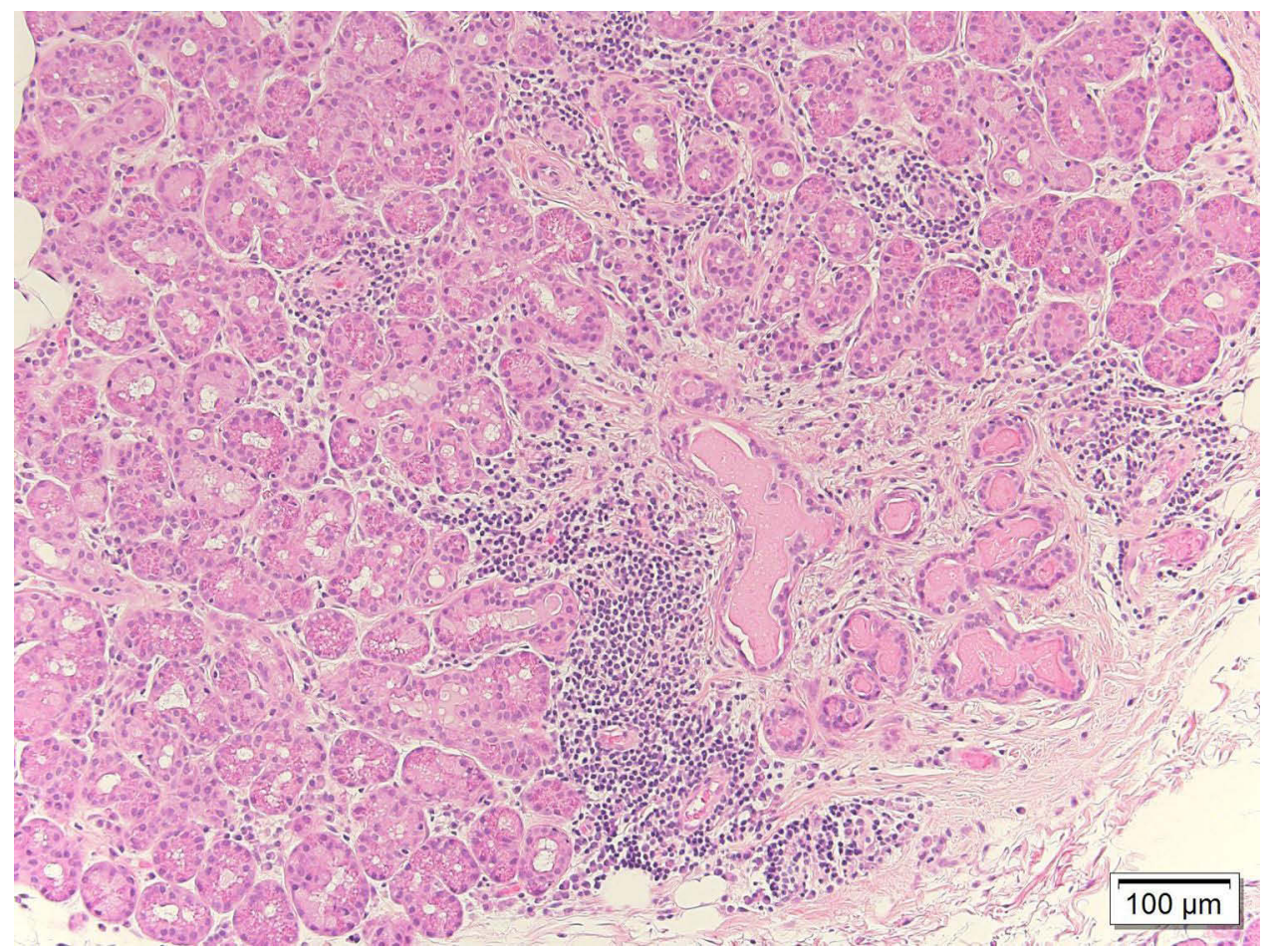

Figure 4 Chronic inflammation showing mixed lymphocytes and plasma cells infiltration (Haematoxylin-Eosin Stain H\&E, magnification XI00).

unlike previous studies that reported a higher incidence of bilateral disease in chronic dacryoadenitis. ${ }^{9,12}$

We observed no statistically significant difference between the non-specific inflammation and lymphoproliferative groups in terms of duration of complaint, gender, or presenting signs, which is comparable to the existing literature. ${ }^{9}$ Among epithelial lesions, pleomorphic adenoma was the most common epithelial lesion affecting the lacrimal gland in our population, accounting for $50 \%$ of all epithelial lesions. A similar finding has been described for tumors of the lacrimal gland. ${ }^{2,10}$

It is known that an isolated lacrimal gland enlargement can be an early sign of thyroid-eye disease. ${ }^{13}$ In 1981, Trokel and Jakobiec described lacrimal gland enlargement in thyroid-related orbitopathy. ${ }^{14}$ Eventually, Harris et al studied the CT scan dimensions of 120 lacrimal glands in Grave's orbitopathy and concluded that the lacrimal gland is significantly enlarged in Grave's orbitopathy. ${ }^{15}$ It is suggested that inflammatory cytokines in thyroid-eye disease are probably associated with the inflammatory involvement of the lacrimal gland. ${ }^{16}$ In our study, a single case was diagnosed with thyroid-related orbitopathy presenting with a history of chronic lacrimal gland enlargement and proptosis.
There is preponderance of the female gender in terms of lacrimal gland involvement; ${ }^{2,4,9}$ similar findings were observed in our analysis. The most common clinical presentation was eyelid swelling (96\%), followed by eyelid erythema (44\%) and proptosis (33\%), compared to the study by Ahn et al in 2019 who described a relatively lower incidence-eyelid swelling (58\%), palpable mass $(36 \%)$, and proptosis $(30 \%){ }^{9}$

Imaging is an important diagnostic tool in lacrimal gland pathologies to characterize these lesions and guide the differential diagnosis and management. ${ }^{17}$ We found the accuracy of CT and MRI scans to be $12 \%$ and $42 \%$, respectively. MRI is superior to CT scan for studying soft tissue, which explains the higher accuracy in lacrimal gland lesions. A study by Bacorn et al in 2020 showed 52\% concordance, and concluded that accurate interpretation of orbital imaging is challenging and that histopathological examination is crucial to arrive at an accurate diagnosis. ${ }^{18}$ Elkhamary et al ${ }^{19,20}$ conducted a study on 42 cases with lacrimal gland masses and found that the apparent diffusion coefficient (ADC) value in diffusion-weighted magnetic resonance imaging (DW-MRI) is a useful, reliable, safe, and non-invasive imaging parameter that can be employed for differentiating between malignant tumors and benign lacrimal lesions with high 
sensitivity and specificity, and to distinguish lymphomas from non-lymphoproliferative lesions. Its superiority can be explained by factors like cellularity, necrosis, and perfusion. ${ }^{21}$ Malignant tumors have cells with enlarged nuclei and reduced extracellular matrix, resulting in a greater restriction in diffusion, along with areas of low signal intensity and low ADC values; whereas, the interstitial changes in benign and inflammatory lesions may lead to increased capillary permeability with extra fluids in the extracellular space, increased intracellular water fraction rather than cellular infiltration, and a subsequent increase in the ADC value. ${ }^{20}$ In our study, interpretation of all radiological images was done by a senior consultant (SE) specialized in orbital pathologies. Figure 5 shows the MRI of a patient diagnosed with lymphoma based on DW-MRI and low ADC values showing a restricted pattern. Extra-nodal marginal zone lymphoma was confirmed on biopsy.

Incisional biopsy is indicated and should not be delayed in both suspected infectious and non-infectious inflammatory lesions that do not respond rapidly to antibiotic therapy, and in other lesions suspected of being neoplastic. ${ }^{22}$ Incisional biopsies of the lacrimal gland are performed by different approaches. ${ }^{23}$ The anterolateral orbitotomy (subperiosteal approach) provides a biopsy from the deep posterior tissue of the orbital lobe of the lacrimal gland. The transeptal approach obtains tissue from the anterior part, whereas the palpebral approach allows biopsy from the palpebral lobe. Wright et al recommended the transeptal approach in the case of a suspected malignancy, as it maintains periosteal integrity and prevents extra-periosteal seeding of malignant cells. ${ }^{24}$ Mombarts et al suggested performing a palpebral lobe biopsy only if the mass is confined to it; otherwise, biopsy of the orbital lobe must be done to avoid damaging the secretory ductules. ${ }^{25}$ In our study, we found no statistically significant differences between the three groups in terms of histopathological outcomes.

Lacrimal gland biopsy can be taken as a single specimen piece or multiple specimen pieces. Mombaerts et al recommended a large biopsy with a minimum volume of $6 \times 6 \times 6 \mathrm{~mm}$, although a biopsy as small as $2 \times 2 \times 2 \mathrm{~mm}$ can be sufficient for laboratory processing. ${ }^{25}$ They also recommended taking samples from several areas within the lesion, as inconclusive pathology often results from sampling limited to the periphery. ${ }^{25}$ In our study, we found that from $45 \%$ of patients, a single specimen piece was obtained (size ranging from $3 \times 2 \mathrm{~mm}$ to $15 \times 10 \mathrm{~mm}$ ), and the final diagnosis was reached in almost all these patients, indicating that histopathology is the gold standard method even when one biopsied sample was obtained. In a previous review of biopsies performed on 60 cases of lacrimal gland inflammation of unknown cause, $61.7 \%$ were found to have specific histopathology, while the remaining $38 \%$ were connected to systemic disease in lacrimal gland inflammation. ${ }^{5}$ In our study population, complete blood investigations were performed in $45.8 \%$ of patients, of which it was diagnostic for only $18.2 \%$. A suggested approach by Teo et $\mathrm{al}^{4}$ for patients with lacrimal gland inflammation is to perform a biopsy to determine the histological diagnosis. Based on the histological diagnosis, a targeted evaluation for a systemic inflammatory disease can be performed in conjunction with a rheumatologist using serological tests, including erythrocyte sedimentation rate, anti-Ro, anti-La, p-antineutrophil cytoplasmic antibody (ANCA), c-ANCA, double-stranded deoxyribonucleic acid (dsDNA), antinuclear antibody (ANA), and thyroid autoantibody titers. Immunoglobulin IgG4 staining can be performed, when available, for patients

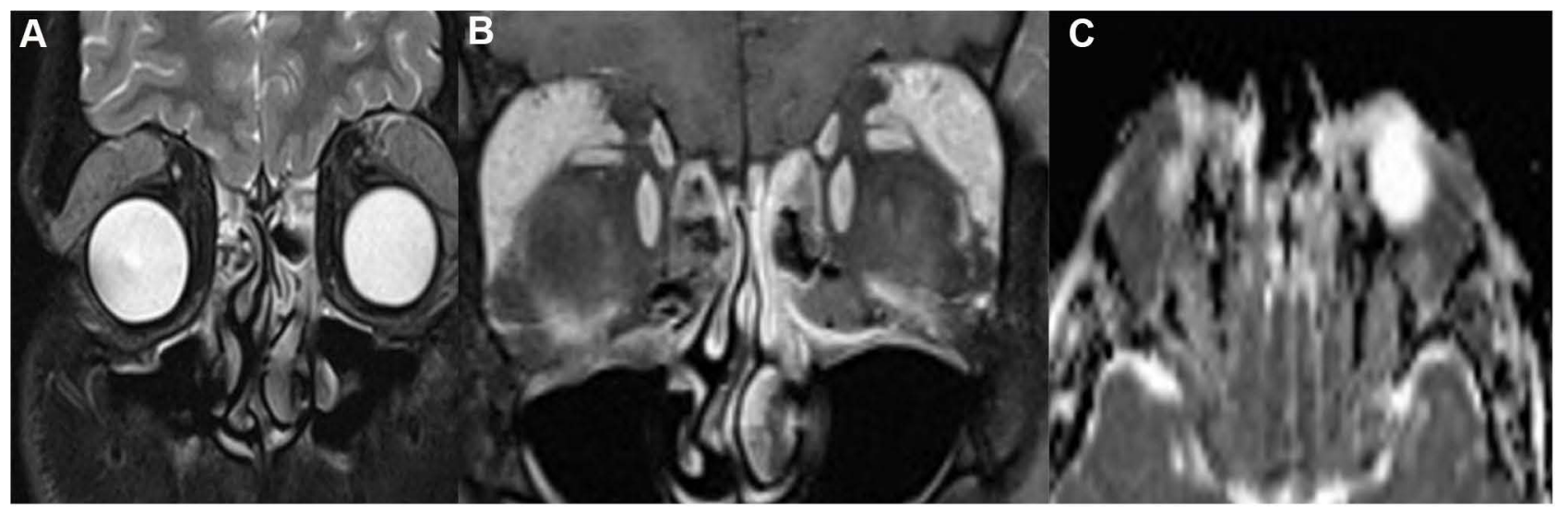

Figure 5 MRI of Extranodal Marginal Zone Lymphoma (A) Coronal fat saturated and post contrast (B) Fat suppressed TI with contrast and apparent diffusion coefficient images (C) Diffusion Weight Image showing restricted pattern (mean $0.85 \times 10 \_3$ ). 
who have a sclerosing inflammation of the orbit on histopathological examination. ${ }^{4}$

The limitations of this study include retrospective study design, limited sample size, non-standardized techniques of examination, decision to operate, and surgical approaches, as more than one surgeon performed the procedure and the surgical approach was based on the surgeon's preference. Further, since our hospital is a tertiary center, there may have been a referral bias that influenced the distribution of pathologies; therefore, our study sample may not be accurately representative of the whole Saudi population with a lacrimal gland mass. Nevertheless, this study is a novel approach to look at the histopathological outcomes of different surgical approaches in lacrimal gland biopsies. Further prospective studies on the surgical techniques to investigate the differences in outcomes and identify different lacrimal gland pathologies are recommended.

\section{Conclusion}

Non-specific inflammation and lymphoproliferative disorders are the most common causes of lacrimal gland lesions in Saudi Arabia. Additionally, thyroid-related orbitopathy needs to be included in the differential diagnosis of lacrimal gland enlargement. Further, blood work-up should not be used to waive off the need for lacrimal gland biopsy, and the diagnosis should preferably be based on histopathology results. MRI is a useful tool to diagnose lacrimal gland lesions; however, histopathology remains the gold standard method. Future studies should focus on prospectively determining the outcome differences for different surgical approaches.

\section{Patients Consent}

Informed consent was obtained from the patient for publication of this case report and any accompanying images. Informed consent was also obtained from all patients to review their medical records, obtain radiological and histopathological images while maintaining their confidentiality.

\section{Disclosure}

The authors declare that there is no conflict of interest in this work.

\section{References}

1. von Holstein SL, Therkildsen MH, Prause JU, Stenman G, Siersma VD, Heegaard S. Lacrimal gland lesions in Denmark between 1974 and 2007. Acta Ophthalmol. 2013;91(4):349-354. doi:10.1111/ j.1755-3768.2012.02403.x
2. Shields CL, Shields JA, Eagle RC, Rathmell JP. Clinicopathologic review of 142 cases of lacrimal gland lesions. Ophthalmology. 1989;96(4):431-435. doi:10.1016/S0161-6420(89)32873-9

3. Andreasen S, Esmaeli B, Von Holstein SL, Hjorth Mikkelsen L, Kristian Rasmussen P, Heegaard S. An update on tumors of the lacrimal gland. Asia Pac J Ophthalmol. 2017. doi:10.22608/ APO. 201707

4. Teo L, Seah LL, Choo CT, Chee SP, Chee E, Looi A. A survey of the histopathology of lacrimal gland lesions in a tertiary referral centre. Orbit. 2013;32(1):1-7. doi:10.3109/01676830.2012.736595

5. Luemsamran P, Rootman J, White VA, Nassiri N, Heran MKS. The role of biopsy in lacrimal gland inflammation: a clinicopathologic study. Orbit. 2017;36(6):411-418. doi:10.1080/01676830.2017.1352608

6. Jung WS, Ahn KJ, Park MR, et al. The radiological spectrum of orbital pathologies that involve the lacrimal gland and the lacrimal fossa. Korean J Radiol. 2007;8(4):336. doi:10.3348/kjr.2007.8.4.336

7. Balchunas WR, Quencer RM, Byrne SF. Lacrimal gland and fossa masses: evaluation by computed tomography and A-mode echography. Radiology. 1983;149(3):751-758. doi:10.1148/ radiology.149.3.6647851

8. Mafee MF, Haik BG. Lacrimal gland and fossa lesions: role of computed tomography. Radiol Clin North Am. 1987;25(4):767-779.

9. Ahn C, Kang S, Sa HS. Clinicopathologic features of biopsied lacrimal gland masses in 95 Korean patients. Graefes Arch Clin Exp Ophthalmol. 2019;257(7):1527-1533. doi:10.1007/s00417-01904327-w

10. Font RL. Malignant epithelial tumors of the lacrimal gland: a clinicopathologic study of 21 cases. Arch Ophthalmol. 1998;116 (5):613. doi:10.1001/archopht.116.5.613

11. Andrew NH, McNab AA, Selva D. Review of 268 lacrimal gland biopsies in an Australian cohort: review of 268 lacrimal gland biopsies. Clin Experiment Ophthalmol. 2015;43(1):5-11. doi:10.1111/ceo.12371

12. Tang SX, Lim RP, Al-Dahmash S, et al. Bilateral lacrimal gland disease: clinical features of 97 cases. Ophthalmology. 2014;121 (10):2040-2046.e1. doi:10.1016/j.ophtha.2014.04.018

13. Yahalomi T, Pikkel J, Arnon R, Soikher E, Rubinov A. Isolated lacrimal gland enlargement in thyroid-related orbitopathy. Case Rep Ophthalmol. 2021;12(1):142-145. doi:10.1159/000514909

14. Trokel SL, Jakobiec FA. Correlation of CT scanning and pathologic features of ophthalmic graves' disease. Ophthalmology. 1981;88 (6):553-564. doi:10.1016/S0161-6420(81)34993-8

15. Harris MA, Realini T, Hogg JP, Sivak-Callcott JA. CT dimensions of the lacrimal gland in graves orbitopathy. Ophthal Plast Reconstr Surg. 2012;28(1):69-72. doi:10.1097/IOP.0b013e31823c4a3a

16. Huang D, Luo Q, Yang H, Mao Y. Changes of lacrimal gland and tear inflammatory cytokines in thyroid-associated ophthalmopathy. Invest Ophthalmol Vis Sci. 2014;55(8):4935. doi:10.1167/iovs.13-13704

17. Sim R, Young SM, Agrawal R, Sundar G. Clinical, radiological and histological correlation in diagnosis of orbital tumours. Cogent Med. 2019;6(1):1607128. doi:10.1080/2331205X.2019.1607128

18. Bacorn C, Gokoffski KK, Lin LK. Clinical correlation recommended: accuracy of clinician versus radiologic interpretation of the imaging of orbital lesions. Orbit. 2021;40(2):133-137. doi:10.1080/ 01676830.2020 .1752742

19. Elkhamary SM. Lacrimal gland lesions: can addition of diffusion-weighted MR imaging improve diagnostic accuracy in characterization? Egypt J Radiol Nucl Med. 2012;43(2):165-172. doi:10.1016/j.ejrnm.2012.02.003

20. ElKhamary SM, Galindo-Ferreiro A, AlGhafri L, Khandekar R, Schellini SA. Characterization of diffuse orbital mass using apparent diffusion coefficient in 3-tesla MRI. Eur $J$ Radiol Open. 2018;5:52-57. doi:10.1016/j.ejro.2018.03.001

21. Razek AAKA, Elkhamary S, Mousa A. Differentiation between benign and malignant orbital tumors at 3-T diffusion MR-imaging. Neuroradiology. 2011;53(7):517-522. doi:10.1007/s00234-011-0838-2 
22. Stewart WB, Krohel GB, Wright JE. Lacrimal gland and fossa lesions: an approach to diagnosis and management. Ophthalmology. 1979;86(5):886-895. doi:10.1016/S0161-6420(79)35467-7

23. Malki AA. Perspective: lacrimal gland biopsy, is it important? Saudi J Ophthalmol. 2009;23(2):141-142. doi:10.1016/j.sjopt.2009.08.001

24. Wright JE, Stewart WB, Krohel GB. Clinical presentation and management of lacrimal gland tumours. $\mathrm{Br} J$ Ophthalmol. 1979;63 (9):600-606. doi:10.1136/bjo.63.9.600
25. Mombaerts I, Rose GE, Garrity JA. Orbital inflammation: biopsy first. Surv Ophthalmol. 2016;61(5):664-669. doi:10.1016/j. survophthal.2016.03.002

\section{Publish your work in this journal}

Clinical Ophthalmology is an international, peer-reviewed journal covering all subspecialties within ophthalmology. Key topics include: Optometry; Visual science; Pharmacology and drug therapy in eye diseases; Basic Sciences; Primary and Secondary eye care; Patient Safety and Quality of Care Improvements. This journal is indexed on PubMed

Submit your manuscript here: https://www.dovepress.com/clinical-ophthalmology-journal
Central and CAS, and is the official journal of The Society of Clinical Ophthalmology (SCO). The manuscript management system is completely online and includes a very quick and fair peer-review system, which is all easy to use. Visit http://www.dovepress.com/ testimonials.php to read real quotes from published authors. 